\title{
BMJ Open Cost-effectiveness analysis of an 18-week exercise programme for patients with breast and colon cancer undergoing adjuvant chemotherapy: the randomised PACT study
}

To cite: May AM, Bosch MJC, Velthuis MJ, et al. Cost-effectiveness analysis of an 18-week exercise programme for patients with breast and colon cancer undergoing adjuvant chemotherapy: the randomised PACT study. BMJ Open 2017;7:e012187. doi:10.1136/bmjopen-2016012187

- Prepublication history and additional material is available. To view please visit the journal (http://dx.doi.org/ 10.1136/bmjopen-2016012187).

Received 8 April 2016 Revised 11 November 2016 Accepted 23 December 2016

CrossMark

For numbered affiliations see end of article.

Correspondence to

Dr Anne M May;

A.M.May@umcutrecht.nl

\section{ABSTRACT}

Objective: Meta-analyses show that exercise interventions during cancer treatment reduce cancerrelated fatigue. However, little is known about the costeffectiveness of such interventions. Here we aim to assess the cost-effectiveness of the 18-week physical activity during cancer treatment (PACT) intervention for patients with breast and colon cancer. The PACT trial showed beneficial effects for fatigue and physical fitness.

Design: Cost-effectiveness analyses with a 9-month time horizon (18 weeks of intervention and 18 weeks of follow-up) within the randomised controlled multicentre PACT study.

Setting: Outpatient clinics of 7 hospitals in the Netherlands (1 academic and 6 general hospitals) Participants: 204 patients with breast cancer and 33 with colon cancer undergoing adjuvant treatment including chemotherapy.

Intervention: Supervised 1-hour aerobic and resistance exercise (twice per week for 18 weeks) or usual care.

Main outcome measures: Costs, quality-adjusted life years (QALY) and the incremental costeffectiveness ratio.

Results: For colon cancer, the cost-effectiveness analysis showed beneficial effects of the exercise intervention with incremental costs savings of $€ 4321$ and QALY improvements of $0.03 .100 \%$ of bootstrap simulations indicated that the intervention is dominant (ie, cheaper and more effective). For breast cancer, the results did not indicate that the exercise intervention was cost-effective. Incremental costs were $€ 2912$, and the incremental effect was 0.01 QALY. At a Dutch threshold value of $€ 20000$ per QALY, the probability that the intervention is cost-effective was $2 \%$.

Conclusions: Our results suggest that the 18-week exercise programme was cost-effective for colon cancer, but not for breast cancer.

Trial registration number: ISRCTN43801571.
Strength and limitations of this study

- We assessed cost-effectiveness prospectively using a multicentre, randomised and pragmatic design.

- The cost-effectiveness analysis was performed from a societal perspective and entails all main costs for the intervention and usual care.

- Costs and effects during the intervention and up to 18 weeks after completing the exercise programme were included.

- About $50 \%$ of control group patients also reported high levels of physical activity, which may have led to an underestimation of the intervention effect.

- Positive intervention effects on fatigue are not necessarily reflected in higher quality of life.

\section{INTRODUCTION}

As a result of improved diagnostics and treatment, survival rates of breast and colon cancer are rising. ${ }^{1}$ Therefore, there is increasing focus on maintaining optimal health in these patients. Fatigue is one of the most common and distressing side effects of cancer and its treatment, and it can persist years after treatment has been completed. ${ }^{23}$ Cancer-related fatigue has been reported to lead to decreased quality of life (QoL), decreased levels of activity and increased absence from work with associated production losses. ${ }^{4}$

Several meta-analyses reported that exercise interventions beneficially affect cancerrelated fatigue. ${ }^{5-7}$ Until now, however, exercise-oncology research has been mainly focused on efficacy or effectiveness, but little is known on the cost-effectiveness. ${ }^{8}$ Since the 
number of cancer survivors is increasing and cancer care needs to be kept affordable, economic evaluations of effective interventions are of importance to guide decision-making. ${ }^{9}$

So far, one randomised controlled trial (RCT) was conducted investigating the cost-effectiveness of a 6-month home-based exercise intervention in patients with breast cancer undergoing adjuvant treatment. ${ }^{10}$ The authors reported a low probability that the intervention was cost-effective compared to a sham flexibility and relaxation programme. Mutrie et $a l^{11}$ showed that patients treated for early-stage breast cancer who were randomised to a 12-week supervised exercise programme reported fewer nights in hospital and fewer visits to the general practitioner than controls, but no cost-effectiveness analysis (CEA) was performed. Hence, RCTs investigating the cost-effectiveness of supervised exercise programmes in patients with cancer during treatment are needed. ${ }^{8}$

We designed the Physical Activity during Cancer Treatment (PACT) study to investigate the (cost-)effectiveness of an 18-week exercise intervention starting early after diagnosis of breast or colon cancer. ${ }^{12}$ We hypothesised that an early start during treatment will lead to less increase in fatigue and a decrease in healthcare-related expenditure. Furthermore, we anticipated that early exercise programmes will lead to a reduction in the absence from work and related production loss and that such programmes will be cost-effective. We recently reported the effects of the PACT exercise programme: physical fatigue was significantly lower in patients with breast cancer and patients with colon cancer who were assigned to the programme compared to usual care. ${ }^{13} 14$ Here, we report the economic evaluation.

\section{METHODS}

The design of the PACT study has been published elsewhere. ${ }^{12}$ In short, the PACT study is a multicentre pragmatic 2-arm RCT. The intervention group received an 18-week aerobic and resistance exercise programme; and the control group received usual care. We performed an economic evaluation from the societal perspective.

\section{Participants}

Patients newly diagnosed with breast cancer or colon cancer and receiving adjuvant chemotherapy participated between 2010 and 2013. Inclusion criteria were histological diagnosis of cancer $<6$ (breast cancer) or 10 (colon cancer) weeks before recruitment; stage M0; scheduled for chemotherapy. Additional inclusion criteria were: age $25-75$ years; not treated for cancer in the 5 years preceding recruitment (except basal skin cancer); able to read and understand the Dutch language; Karnofsky Performance Status $\geq 60$; able to walk $\geq 100 \mathrm{~m}$; no contraindications for physical activity. The study has been approved by the Institutional Review Board of the University Medical Center Utrecht and the local Review Boards of the participating hospitals. Written informed consent has been obtained from all patients.

\section{Randomisation procedure}

Concealed randomisation of patients was stratified per tumour site (breast or colon) by the sequential balancing method. The following characteristics were balanced: age (25-40, 40-65 and 65-75 years), adjuvant treatment (radiotherapy yes/no); using a tissue expander (yes/no (breast cancer)), hospital and gender (colon cancer).

\section{Exercise intervention}

The 18-week exercise programme was offered at seven outpatient clinics of hospitals in the Netherlands, twice weekly. The programme was individualised to the patient's personal preferences and fitness level. The 1-hour exercise classes included a warming up ( $5 \mathrm{~min}$ ), aerobic and muscle strength training $(50 \mathrm{~min})$ and a cooling down $(5 \mathrm{~min})$. In addition to the supervised exercise programme, patients were recommended to be physically active for at least $30 \mathrm{~min}$ a day on at least three other days. ${ }^{15}$ More details of the programme have been described elsewhere. ${ }^{12-14}$

\section{Control group}

Participants randomised to control received usual care and were asked to maintain their habitual physical activity pattern up to week 18 . Thereafter, participants were allowed, for ethical reasons, to participate in exercise programmes offered routinely after cancer treatment.

\section{Measurements}

Participants visited the study centre for outcome assessment at baseline, postintervention (18 weeks) and at 36 weeks. Participants filled out diaries (on paper) once a week to assess health services usage, use of complementary medicine, absence from work, domestic help, out-of-pocket costs, travel expenses of the corresponding week. Patients returned the first diary at 18 weeks and received a second diary for the following 18 weeks. Since some effects may only occur in the long term, ${ }^{8}$ the present CEA covers the total 36-week study period.

\section{Economic evaluation}

\section{Costs}

Since the time frame was $<1$ year, no discounting was performed. Missing cost data were imputed per cost component with single imputation, using the Markov chain Monte Carlo (MCMC) method taking into account all other cost information, as well as tumour type, age, gender and randomisation group.

\section{Volumes of resources used}

Productivity losses (related to being absent at work and being less productive while working) were measured every 4 weeks using the Short Form-Health and Labour 
questionnaire (SF-HLQ), ${ }^{16}$ which was included in the patients' diary.

Data on cancer therapy (ie, chemotherapy, immunotherapy, hormone therapy, radiotherapy) were obtained from medical records.

\section{Cost prices}

We used price levels of 2011 and indexed prices where necessary using the consumer price index from Statistics Netherlands. ${ }^{17}$ A detailed description of cost prices is given in online supplementary file 1.

\section{Physical exercise intervention costs}

For the intervention group, the volume of PACT sessions was derived from attendance registration. The costs of the PACT intervention were calculated with the bottom-up microcosting method. First, the physiotherapist wage costs were determined according to the Dutch guidelines for cost research. ${ }^{18}$ Income was assessed from the hospitals' collective bargaining agreement. The remaining costs (eg, room rental, overhead, equipment depreciation) were based on agreements between the hospitals and the research group and are estimated at $€ 4.50$ per session. Costs for one session were $€ 55.00$. These costs per session were divided by the mean number of patients present per session (2.5) resulting in a cost price per patient per session (€22.18). Costs of the individual intake session were estimated at $75 \%$ (45 min instead of 60) of the cost price of the regular PACT sessions (€41.25).

\section{Utilities and quality-adjusted life-years}

The EQ-5D $\mathrm{D}^{19}$ was included in the patients' diary and assessed every 4 weeks. We used the Dutch EQ-5D tariff to convert the patients' health status into a utility value. ${ }^{20}$

Quality-adjusted life years (QALYs) were calculated, using an area under the curve method for the total observation period of 36 weeks, as the sum of the average QoL score within 9 observation periods of 4 weeks, each multiplied by $28 / 365.25$ ( 4 weeks). To accommodate for differences in baseline QoL (baseline EQ5D score), adjusted QALYs were calculated over the 36-week observation period, following a regression analysis-based method as proposed by Manca et al. ${ }^{21}$ These adjusted QALYs were used as effect measure in all cost-effectiveness calculations.

Missing QoL scores were imputed with the single imputation method, using the MCMC method taking into account QoL scores from other time points, as well as tumour type, age, gender and randomisation group.

\section{Statistical analysis}

Intention to treat analyses was performed separately for breast cancer and colon cancer in order to address sitespecific issues (eg, differences in treatment). Baseline characteristics of patients with and without cost data were compared with an independent t-test for normally distributed data, the Mann-Whitney $U$ test for nonparametric data and the Pearson's $\chi^{2}$ test for categorical data.

The incremental cost-effectiveness ratio (ICER) was calculated as the difference in costs divided by the difference in QALYs between the intervention and control groups using a bootstrap analysis with 5000 simulations. From the bootstrap analysis, a cost-effectiveness plane was produced, each quadrant indicating whether the intervention is more or less expensive and more or less effective compared to usual care. Moreover, costeffectiveness acceptability curves (CEACs) are presented to illustrate decision uncertainty. ${ }^{22}$ The CEAC shows the probability that the exercise intervention is cost-effective compared to usual care, for a range of threshold values for willingness to pay $(\lambda)$ per additional QALY. In the Netherlands, threshold values of $€ 20000$ to $€ 80000$ per QALY are commonly used. ${ }^{23}$

\section{Sensitivity analysis}

In the current population, cancer treatment is the largest cost component. Since, for patients with breast cancer, tumour receptor status was differently distributed between the intervention and control groups, which influences treatment costs, we performed sensitivity analyses excluding radiotherapy and cancer therapy from the analyses. Furthermore, we performed sensitivity analysis excluding patients with Her2Neu+tumour, who were more often randomised to the intervention and who received a relative expensive and long-term immunotherapy treatment.

The cost-(effectiveness) was also calculated from a healthcare perspective, excluding all non-healthcare costs, such as productivity losses, out-of-pocket costs of patients and unpaid home help. Since costs for the PACT intervention only affect the intervention group, a deviation in the cost price might have a large effect on the incremental costs. Therefore, we examined the effect of an increase and a decrease of $50 \%$ of intervention costs.

\section{RESULTS}

For the economic analysis, data of 194 (82\%) patients from the PACT study were available (see online supplementary figure 1 ). The 43 patients who did not complete their diaries did not differ from the participants with respect to age, gender, use of tissue expander, type of cancer, use of radiotherapy, tumour receptor status and menopausal status ( $p$ value $>0.05$ ). Only BMI was significantly higher in the patients who dropped out $\left(27.9 \pm 5.8 \mathrm{~kg} / \mathrm{m}^{2}\right.$ vs $\left.25.7 \pm 4.2 \mathrm{~kg} / \mathrm{m}^{2} ; \mathrm{p}=0.02\right)$. Of 194 patients (16\%), 30 did not provide the second diary (covering weeks 19-36). For two patients, detailed information about radiotherapy was missing, once because of incomplete data in the patient record and once because the patient denied access to medical records. 
Baseline characteristics were similar between treatment arms, with the exception that patients with breast cancer in the intervention group were higher educated, more often postmenopausal and more often diagnosed with a triple negative tumour (table 1 ).

Patients with breast cancer and colon cancer in the intervention group attended $83 \%$ (IQR 69-91\%) and $89 \%(72-97 \%)$ of the offered exercise classes, respectively.

\section{Costs}

Table 2 shows resource use and associated costs. For patients with breast cancer, costs for the exercise intervention and costs for chemotherapy and radiotherapy, absence from work and domestic help were higher in the intervention group compared to control, explaining the incremental cost difference between groups of
$€ 2890$. For patients with colon cancer, costs for chemotherapy, hospitalisation, medical contacts and absence from work were lower in the intervention group compared to control, while costs for the exercise intervention and domestic help were higher. The incremental cost difference between groups was $€ 4305$.

\section{EQ5D scores}

For patients with breast cancer, differences in average EQ5D scores during the 18-week intervention period in the intervention and control groups were comparable (mean difference $0.001(-0.04$ to 0.04$)$ ), and during the 18-week follow-up differences in average EQ5D scores were $0.02(-0.03$ to 0.06$)$ higher in the intervention group. Differences in average EQ5D scores over the 36 -week study period were not different between the intervention and control groups $(0.01$ (95\% CI -0.02 to

Table 1 Baseline characteristics of participants of the PACT study included in the cost-effectiveness analyses*

\begin{tabular}{|c|c|c|c|c|}
\hline \multirow[b]{2}{*}{ Age (years) } & \multicolumn{2}{|l|}{ Breast cancer } & \multicolumn{2}{|l|}{ Colon cancer } \\
\hline & $\begin{array}{l}\text { Intervention }(\mathrm{N}=87) \\
50.0 \pm 7.9\end{array}$ & $\begin{array}{l}\text { Control }(\mathrm{N}=78) \\
49.4 \pm 7.6\end{array}$ & $\begin{array}{l}\text { Intervention }(\mathrm{N}=14) \\
57.4 \pm 11.2\end{array}$ & $\begin{array}{l}\text { Control }(\mathrm{N}=15) \\
59.1 \pm 8.9\end{array}$ \\
\hline \multicolumn{5}{|l|}{ Educational status } \\
\hline Low & $2(2 \%)$ & $12(15 \%)$ & $1(7 \%)$ & $2(13 \%)$ \\
\hline Medium & $40(46 \%)$ & $33(42 \%)$ & $6(43 \%)$ & $4(27 \%)$ \\
\hline High & $43(49 \%)$ & $33(42 \%)$ & $7(50 \%)$ & $9(60 \%)$ \\
\hline Missing & $2(2 \%)$ & $0(0 \%)$ & $0(0 \%)$ & $0(0 \%)$ \\
\hline \multicolumn{5}{|l|}{ Marital status } \\
\hline Alone & $17(20 \%)$ & $14(18 \%)$ & $4(29 \%)$ & $5(33 \%)$ \\
\hline Married/living together & $70(81 \%)$ & $64(82 \%)$ & $10(71 \%)$ & $10(67 \%)$ \\
\hline \multicolumn{5}{|l|}{ Gender } \\
\hline Male & $0(0 \%)$ & $0(0 \%)$ & $7(50 \%)$ & $11(73 \%)$ \\
\hline Female & $87(100 \%)$ & $78(100 \%)$ & 7 (50\%) & $4(27 \%)$ \\
\hline \multicolumn{5}{|l|}{ Tissue expander } \\
\hline Yes & $9(10 \%)$ & $8(10 \%)$ & - & - \\
\hline No & $78(90 \%)$ & $70(90 \%)$ & - & - \\
\hline \multicolumn{5}{|l|}{ Radiotherapy } \\
\hline Yes & $60(69 \%)$ & $52(67 \%)$ & $1(7 \%)$ & $1(7 \%)$ \\
\hline No & $27(31 \%)$ & $26(33 \%)$ & $13(93 \%)$ & $14(93 \%)$ \\
\hline \multicolumn{5}{|l|}{ Chemotherapy } \\
\hline FEC/DOC & $54(62 \%)$ & $53(68 \%)$ & - & - \\
\hline AC/paclitaxel trastuzumab & $16(18 \%)$ & $10(13 \%)$ & - & - \\
\hline TAC & $17(20 \%)$ & $15(19 \%)$ & - & - \\
\hline CAPOX & - & - & $13(93 \%)$ & $15(100 \%)$ \\
\hline Capecitabine mono & - & - & $1(7 \%)$ & $0(0 \%)$ \\
\hline \multicolumn{5}{|l|}{ Tumour receptor status } \\
\hline Triple- & $20(23 \%)$ & $8(10 \%)$ & - & - \\
\hline Her2Neu+\&ER or PR+ & $10(12 \%)$ & $11(14 \%)$ & - & - \\
\hline Her2Neu+\&ER and PR- & $10(12 \%)$ & $2(3 \%)$ & - & - \\
\hline Her2Neu-\&ER or PR+ & $47(54 \%)$ & $57(73 \%)$ & - & - \\
\hline \multicolumn{5}{|l|}{ Menopausal status } \\
\hline Postmenopausal & $39(45 \%)$ & $23(30 \%)$ & $3(21 \%)$ & $3(20 \%)$ \\
\hline Premenopausal & $40(46 \%)$ & $53(68 \%)$ & $3(21 \%)$ & $0(0 \%)$ \\
\hline Not applicable (male) & - & - & $7(50 \%)$ & $11(73 \%)$ \\
\hline Missing & $8(9 \%)$ & $2(3 \%)$ & $1(7 \%)$ & $1(7 \%)$ \\
\hline Body mass index $\left(\mathrm{kg} / \mathrm{m}^{2}\right)$ & $25.3 \pm 4.2$ & $25.8 \pm 4.5$ & $26.8 \pm 4.4$ & $26.0 \pm 2.9$ \\
\hline
\end{tabular}




\begin{tabular}{|c|c|c|c|c|c|c|c|c|c|}
\hline \multirow[b]{3}{*}{ Cost component } & \multirow[b]{3}{*}{ Unit costs/unit $(€)$} & \multicolumn{4}{|l|}{ Breast cancer } & \multicolumn{4}{|l|}{ Colon cancer } \\
\hline & & \multicolumn{2}{|c|}{ Intervention $(\mathrm{n}=\mathbf{8 7})$} & \multicolumn{2}{|l|}{ Control (N=78) } & \multicolumn{2}{|c|}{ Intervention $(n=14)$} & \multicolumn{2}{|l|}{ Control (N=15) } \\
\hline & & $\begin{array}{l}\text { Mean number } \\
\text { of units (SD) }\end{array}$ & $\begin{array}{l}\text { Mean total } \\
\text { costs } € \text { (SD) }\end{array}$ & $\begin{array}{l}\text { Mean number } \\
\text { of units (SD) }\end{array}$ & $\begin{array}{l}\text { Mean total } \\
\text { costs } €(S D)\end{array}$ & $\begin{array}{l}\text { Mean number } \\
\text { of units (SD) }\end{array}$ & $\begin{array}{l}\text { Mean total } \\
\text { costs } €(\text { (SD) }\end{array}$ & $\begin{array}{l}\text { Mean number } \\
\text { of units (SD) }\end{array}$ & $\begin{array}{l}\text { Mean total } \\
\text { costs } € \text { (SD) }\end{array}$ \\
\hline \multicolumn{10}{|l|}{ Direct healthcare costs } \\
\hline Medication & Individualised & - & $575(668)$ & - & $589(608)$ & - & $176(186)$ & - & $377(431)$ \\
\hline Cancer therapy & Individualised & - & $9844(7676)$ & - & 8954 (6407) & - & $9376(3476)$ & - & $11260(3190)$ \\
\hline Radiotherapy & 230 & $14.9(12.8)$ & 3421 (2942) & $13.5(12.5)$ & 3096 (2864) & $0(0)$ & $0(0)$ & $0(0)$ & $0(0)$ \\
\hline Hospital days & 465.80 & $1.9(3.1)$ & $944(1453)$ & $1.6(2.8)$ & $842(1289)$ & $2.6(4.6)$ & 1253 (2102) & $8.8(11.8)$ & $4282(5464)$ \\
\hline Day care & 200.12 & $0.3(0.7)$ & $72(136)$ & $0.4(1.2)$ & $95(230)$ & $0.4(0.6)$ & $76(124)$ & $0.4(0.8)$ & $97(166)$ \\
\hline Consults medical specialist & 74.42 & $13.4(7.4)$ & $1055(522)$ & $12.8(6.8)$ & $1054(466)$ & $12.1(6.5)$ & $938(461)$ & $12.4(8.1)$ & $1088(519)$ \\
\hline Consults other caregivers & Appendix 1 & $31.6(20.4)$ & 1417 (879) & $31.9(22.7)$ & 1535 (992) & $20.9(16.9)$ & $1043(907)$ & $21.9(29.9)$ & $1178(1173)$ \\
\hline $\begin{array}{l}\text { Phone consults medical } \\
\text { specialists }\end{array}$ & 37.21 & $1.8(2.7)$ & $73(102)$ & $1.6(2.1)$ & $68(75)$ & $1.9(2.4)$ & $73(89)$ & $2.7(3.7)$ & $115(131)$ \\
\hline $\begin{array}{l}\text { Phone consults other } \\
\text { caregivers }\end{array}$ & Appendix 1 & $5.8(8.1)$ & $128(200)$ & $4.8(6.6)$ & $102(128)$ & $4.2(2.7)$ & $87(53)$ & $3.0(3.7)$ & $79(86)$ \\
\hline Professional home care & 36.27 & $1.3(5.3)$ & $62(191)$ & $3.3(14.8)$ & $136(535)$ & $15.6(49.8)$ & $573(1804)$ & $2.5(7.4)$ & $114(265)$ \\
\hline \multicolumn{10}{|l|}{ Direct non-healthcare costs } \\
\hline Paid domestic help & 36.27 & $8.9(22.2)$ & $348(804)$ & $4.4(17.3)$ & $190(624)$ & $9.6(29.4)$ & 360 (1066) & $0.3(1.1)$ & $59(86)$ \\
\hline Patient travel costs & Individualised & - & $436(182)$ & - & 430 (199) & - & $189(82)$ & - & $228(127)$ \\
\hline Patient own costs & Individualised & - & $456(762)$ & - & $381(1188)$ & - & $46(58)$ & - & $279(321)$ \\
\hline \multicolumn{10}{|l|}{ Indirect non-healthcare costs } \\
\hline Unpaid domestic help & 12.96 & $78.3(118.5)$ & $1104(1511)$ & $62.9(82.6)$ & 934 (1025) & $88.4(186.7)$ & $1186(2418)$ & $17.7(31.6)$ & $411(427)$ \\
\hline Sick leave (in hours) & Individualised & $185.0(153.6)$ & $4378(3650)$ & $161.5(133.4)$ & 3808 (3120) & $177.9(155.1)$ & 4887 (4335) & $207.8(147.6)$ & $5826(4371)$ \\
\hline \multicolumn{10}{|l|}{ PACT costs } \\
\hline \multicolumn{10}{|l|}{ Direct healthcare costs } \\
\hline Pact sessions & 22.18 & $28.2(5.7)$ & $626(126)$ & $0(0)$ & $0(0)$ & $29.4(6.2)$ & $651(137)$ & $0(0)$ & $0(0)$ \\
\hline Pact intake & 41.25 & $1.0(0.0)$ & $41(0)$ & $0(0)$ & $0(0)$ & $1.0(0.0)$ & $41(0)$ & $0(0)$ & $0(0)$ \\
\hline \multicolumn{10}{|l|}{ Direct non-healthcare } \\
\hline Pact travelling costs & 4.35 & $29.2(5.7)$ & $127(25)$ & $0(0)$ & $0(0)$ & $30.4(6.2)$ & $132(27)$ & $0(0)$ & $0(0)$ \\
\hline \multicolumn{10}{|l|}{ Total costs $(€)$} \\
\hline Societal perspective & & - & 25105 (10 403) & - & 22215 (8652) & - & 21086 (7037) & - & 25391 (7131) \\
\hline Healthcare perspective & & - & $18195(8517)$ & - & 16335 (7225) & - & 13713 (3956) & - & $18474(6252)$ \\
\hline
\end{tabular}


$0.03)$ and 0.01 ( -0.02 to 0.02$)$ after adjustment for differences in the baseline EQ5D score, table 3).

Differences in average EQ5D scores of patients with colon cancer in the intervention group, compared to the control group, were $0.02(-0.06$ to 0.11$)$ and 0.11 (0.03 to 0.18 ) higher during the 18-week intervention period and the following 18 weeks, respectively. The total incremental effect for patients with colon cancer was $0.04(-0.01$ to 0.09$)$. Adjustment for differences in the baseline EQ5D score diminished the difference between intervention groups to 0.03 ( -0.01 to 0.06 ).

\section{Economic analyses}

For patients with breast cancer, bootstrapping revealed incremental costs (cost difference between groups) of $€ 2912$ and an incremental effect of 0.01 ; therefore, the ICER was €403.394/QALY. From the bootstrap analysis (figure 1), it appeared that almost all simulations showed higher costs for the intervention, with small positive or negative QALY differences between intervention and control. Figure 2 shows that if society is willing to pay (WTP) either $€ 20000$ or $€ 80000$ per additional QALY, the probability that the intervention would be cost-effective for patients with breast cancer is $2 \%$ and $6 \%$, respectively.

For patients with colon cancer, the incremental cost savings were $€ 4321$ and the incremental effectiveness of the PACT intervention compared to control was 0.03 QALYs. This implies that the PACT intervention dominates usual care, as it generates lower costs and better effects. All 5000 bootstrap samples indicate that the intervention is dominant for patients with colon cancer (figure 1). Since the probability of acceptance at a certain WTP cannot be lower than the percentage of simulations indicating dominance, the probability that the intervention is cost-effective is $100 \%$ at every level of WTP.

Table 3 Mean health-related quality of life during the 18-week intervention period and 18-week follow-up and the QALYs by cancer type and group allocation

\begin{tabular}{|c|c|c|c|}
\hline & $\begin{array}{l}\text { Intervention (mean (SD)) } \\
\mathrm{n}=87\end{array}$ & $\begin{array}{l}\text { Control (mean (SD)) } \\
\mathrm{n}=78\end{array}$ & Mean difference $(95 \% \mathrm{Cl})$ \\
\hline \multicolumn{4}{|l|}{ Breast cancer } \\
\hline \multicolumn{4}{|l|}{ EQ-5D score } \\
\hline Baseline & $0.88(0.13)$ & $0.87(0.13)$ & $0.01(-0.03$ to 0.05$)$ \\
\hline 4 weeks & $0.85(0.18)$ & $0.84(0.17)$ & $0.01(-0.04$ to 0.06$)$ \\
\hline 8 weeks & $0.82(0.19)$ & $0.80(0.20)$ & $0.02(-0.04$ to 0.08$)$ \\
\hline 12 weeks & $0.78(0.24)$ & $0.80(0.20)$ & $-0.01(-0.08$ to 0.06$)$ \\
\hline 16 weeks & $0.80(0.21)$ & $0.82(0.17)$ & $-0.02(-0.08$ to 0.04$)$ \\
\hline 20 weeks & $0.84(0.12)$ & $0.82(0.17)$ & $0.01(-0.03$ to 0.06$)$ \\
\hline 24 weeks & $0.82(0.16)$ & $0.77(0.20)$ & $0.05(-0.01$ to 0.10$)$ \\
\hline 28 weeks & $0.79(0.21)$ & $0.78(0.18)$ & $0.01(-0.06$ to 0.07$)$ \\
\hline 32 weeks & $0.83(0.17)$ & $0.80(0.19)$ & $0.02(-0.03$ to 0.08$)$ \\
\hline 36 weeks & $0.82(0.17)$ & $0.82(0.19)$ & $-0.004(-0.06$ to 0.05$)$ \\
\hline Average EQ-5D score during first 18 weeks & $0.83(0.14)$ & $0.83(0.12)$ & $0.001(-0.04-0.04)$ \\
\hline Average EQ-5D score during last 18 weeks & $0.82(0.13)$ & $0.80(0.14)$ & $0.02(-0.03-0.06)$ \\
\hline QALY total over 36 weeks & $0.566(0.08)$ & $0.559(0.08)$ & $0.007(-0.02 ; 0.03)$ \\
\hline \multirow[t]{2}{*}{ QALY total over 36 weeks (adjusted)* } & $0.569(0.03)$ & $0.560(0.04)$ & $0.009(-0.02 ; 0.02)$ \\
\hline & $n=14$ & $n=15$ & \\
\hline \multicolumn{4}{|l|}{ Colon cancer } \\
\hline \multicolumn{4}{|l|}{ EQ-5D score } \\
\hline Baseline & $0.89(0.11)$ & $0.82(0.19)$ & $0.07(-0.05$ to 0.19$)$ \\
\hline 4 weeks & $0.84(0.12)$ & $0.77(0.17)$ & $0.07(-0.04$ to 0.18$)$ \\
\hline 8 weeks & $0.79(0.16)$ & $0.80(0.18)$ & $-0.01(-0.14$ to 0.12$)$ \\
\hline 12 weeks & $0.79(0.20)$ & $0.80(0.18)$ & $-0.01(-0.16$ to 0.14$)$ \\
\hline 16 weeks & $0.83(0.11)$ & $0.82(0.11)$ & $0.001(-0.09$ to 0.09$)$ \\
\hline 20 weeks & 0.90 (0.09) & $0.86(0.10)$ & $0.04(-0.03$ to 0.12$)$ \\
\hline 24 weeks & $0.90(0.01)$ & $0.83(0.13)$ & $0.07(-0.02$ to 0.15$)$ \\
\hline 28 weeks & $0.89(0.11)$ & $0.73(0.21)$ & $0.16(0.03$ to 0.29$)$ \\
\hline 32 weeks & $0.90(0.12)$ & $0.79(0.15)$ & $0.12(0.01$ to 0.22$)$ \\
\hline 36 weeks & $0.89(0.13)$ & $0.74(0.21)$ & $0.14(0.01$ to 0.28$)$ \\
\hline Average EQ-5D score during first 18 weeks & $0.83(0.10)$ & $0.80(0.12)$ & $0.02(-0.06$ to 0.11$)$ \\
\hline Average EQ-5D score during last 18 weeks & $0.90(0.07)$ & $0.79(0.12)$ & $0.11(0.03$ to 0.18$)$ \\
\hline QALY total over 36 weeks & $0.593(0.05)$ & $0.551(0.07)$ & $0.042(-0.01$ to 0.09$)$ \\
\hline QALY total over 36 weeks (adjusted)* & $0.572(0.03)$ & $0.546(0.05)$ & $0.026(-0.01$ to 0.06$)$ \\
\hline
\end{tabular}


Figure 1 Cost-effectiveness plane from 5000 bootstrap simulations for the PACT intervention compared to usual care, separately for patients with breast cancer and colon cancer. PACT, physical activity during cancer treatment.
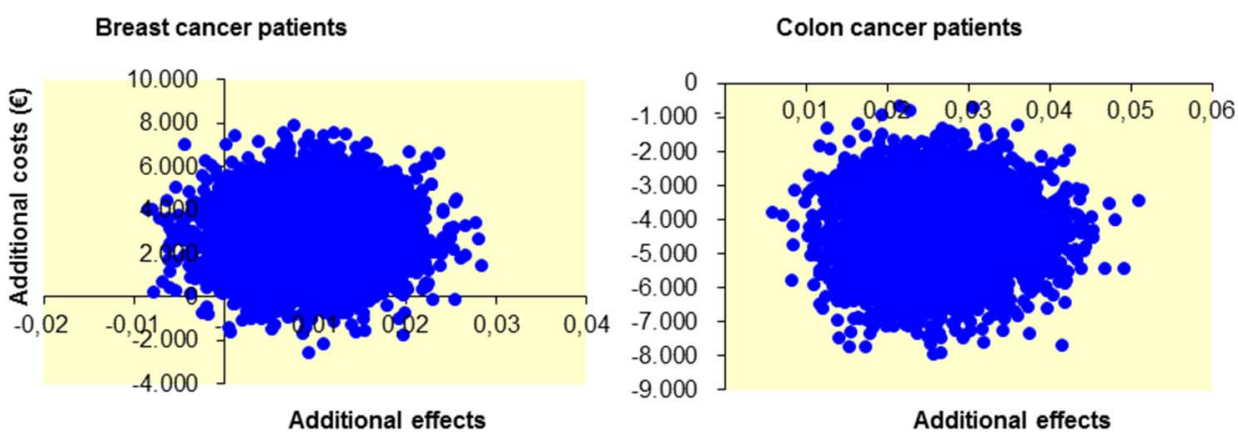

Figure 2 Cost-effectiveness acceptability curve of the PACT intervention compared to usual care, for patients with breast cancer. Note that the intervention is dominant for patients with colon cancer. Therefore, generation of a cost-effectiveness acceptability curve became redundant. ICER, incremental cost-effectiveness ratio; PACT, physical activity during cancer treatment.

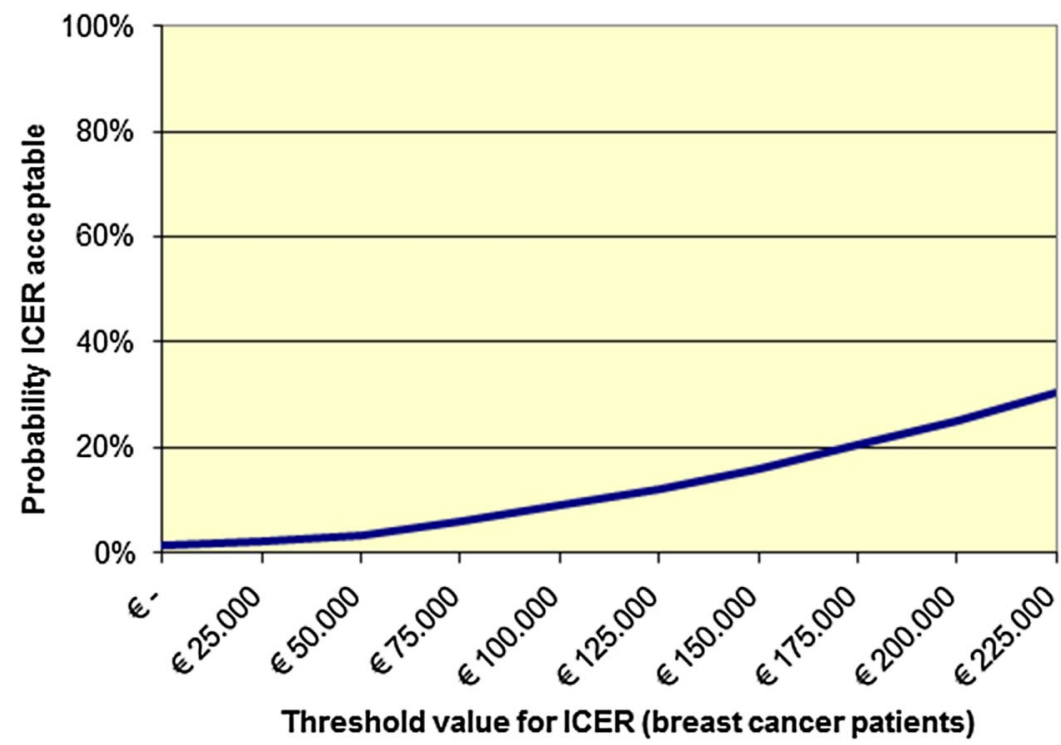

Sensitivity analyses

Results of all sensitivity analyses were similar to results of the baseline analysis (table 4).

\section{DISCUSSION}

The present study indicates that for patients with colon cancer, the 18-week exercise intervention starting as soon as possible after diagnosis was less costly and more effective. As anticipated, the intervention group had a lower healthcare usage and reported less hours of absence from work compared to usual care. The probability that the intervention is cost-effective was $100 \%$ at every level of WTP for a QALY. Patients with breast cancer who were randomised to the exercise intervention incurred higher costs and no apparent effects on QoL. For patients with breast cancer, the probability of being cost-effective was low, even at a relatively high threshold value of $€ 80000$ per QALY (6\%).

Economic evaluations of exercise-oncology interventions are scarce, and different interventions were assessed. ${ }^{8}$ One RCT investigated the cost-effectiveness of an exercise programme during adjuvant treatment for breast cancer, but the interventions were not comparable. ${ }^{10}$ This study, comparing a 6-month home-based exercise programme to flexibility training during any adjuvant treatment, reported that the intervention was not cost-effective. Another randomised trial did not perform a CEA, but reported that patients with breast cancer who participated in a 12-week supervised exercise programme reported less nights in hospital and less visits to their general practitioner compared to usual care. ${ }^{11}$ We cannot confirm this finding in our study where we found no substantial differences in number of hospital days and caregiver consults. Mewes $e t a l^{24}$ performed a CEA of a 12-week home-based exercise programme using data of an RCT including patients with breast cancer after primary treatment with menopausal symptoms. The incremental cost-utility ratio was $€ 28078$ /QALY, which is considerably lower than our findings. This might be explained by the difference in setting, that is, during versus after primary cancer treatment. Moreover, costs were estimated instead of assessed at an individual basis as was performed in the PACT study.

For colon cancer, there is no CEA published for exercise interventions. In our study, intervention patients reported less hospital days compared to the usual care group. This was also noticed in the study of Mutrie et al. ${ }^{11}$ However, we observed a comparable number of caregiver consults in the intervention and control groups.

Even after correction for baseline differences, we found larger benefits from the intervention in patients 
Table 4 Results of sensitivity analyses

\begin{tabular}{|c|c|c|c|c|c|c|}
\hline & $\begin{array}{l}\text { Incremental } \\
\text { effect }\end{array}$ & $\begin{array}{l}\text { Incremental } \\
\text { costs }\end{array}$ & ICER €/QALY & Dominance (\%) & $\begin{array}{l}\text { Probability } \\
\text { cost-effective } \\
\lambda=€ 20.000 \text { (\%) }\end{array}$ & $\begin{array}{l}\text { Probability } \\
\text { cost-effective } \\
\lambda=€ 80.000 \text { (\%) }\end{array}$ \\
\hline \multicolumn{7}{|c|}{ Healthcare perspective } \\
\hline Breast $(n=165)$ & 0.01 & 1861 & 432.644 & 5 & 8 & 17 \\
\hline Colon $(n=29)$ & 0.03 & -4743 & $D^{*}$ & 100 & 100 & 100 \\
\hline \multicolumn{7}{|c|}{ Without radio and cancer therapy $\dagger$} \\
\hline Breast $(n=165)$ & 0.01 & 1638 & 200.134 & 2 & 4 & 16 \\
\hline Colon $(n=29)$ & 0.03 & -2393 & $\mathrm{D}^{*}$ & 100 & 99 & 100 \\
\hline \multicolumn{7}{|c|}{ Subgroup no immunotherapy } \\
\hline Breast $(n=131)$ & 0.01 & 1759 & 299.495 & 4 & 6 & 17 \\
\hline \multicolumn{7}{|c|}{ Maximum cost price PACT (150\%) } \\
\hline Breast $(n=165)$ & 0.01 & 3214 & 4399.548 & 1 & 2 & 6 \\
\hline Colon $(n=29)$ & 0.03 & -3930 & $D^{*}$ & 100 & 100 & 100 \\
\hline \multicolumn{7}{|c|}{ Minimum cost price PACT (50\%) } \\
\hline Breast $(n=165)$ & 0.01 & 2560 & 261.030 & 4 & 6 & 13 \\
\hline Colon $(n=29)$ & 0.03 & -4638 & $\mathrm{D}^{*}$ & 100 & 100 & 100 \\
\hline
\end{tabular}

with colon cancer than in those with breast cancer. Since patients with colon cancer were recruited in the same period and in the same hospitals and study centres, differences cannot be explained by a difference in setting. Also, for physical fatigue and physical fitness, we found larger effects in patients with colon cancer ${ }^{14}$ than in those with breast cancer. ${ }^{13}$ This may partly explain the beneficial economic evaluation in patients with colon cancer. Surgery in colon cancer is on average more extensive compared to breast cancer surgery, so maybe exercise is more effective because it supports recovery and there is more room for improvement in colon cancer. Another speculation is that chemotherapy given for colon cancer has less effect on fatigue levels in patients and therefore larger improvements are possible. Also, while $71 \%$ of our patients with breast cancer received radiotherapy, those with colon cancer did not. Radiotherapy may also increase fatigue levels. ${ }^{25}$ In the PACT study, physical and general fatigue levels increased during chemotherapy in patients with breast cancer of the intervention group, ${ }^{13}$ whereas general fatigue remained stable and physical fatigue already decreased significantly during the intervention in patients with colon cancer. ${ }^{14}$ However, it should be noted that we were able to include only 29 patients with colon cancer in our study and the results need to be confirmed in a larger study.

Interestingly, costs for paid and unpaid domestic help were higher for breast cancer and colon cancer in the intervention group compared to control. Reasons for this might be that the intervention caused less time left for domestic tasks and/or that family and friends were supporting patients to be able to participate in the time-consuming and physically demanding exercise programme.
In a CEA, QoL (assessed by the EQ-5D) is typically used as a measure of effectiveness, whereas the PACT exercise intervention was designed to prevent fatigue symptoms. Effects on QoL have rarely been reported when evaluating exercise interventions during cancer treatment, but beneficial effects on fatigue were found in the PACT study and other studies. ${ }^{13}$ 14 $26-28$ Apparently, these positive effects on fatigue are not reflected in higher QoL as measured by EQ-5D, at least not for breast cancer.

The strength of this study is its multicentre, randomised and pragmatic design. Compared to an explanatory trial, a pragmatic trial better reflects usual daily conditions and is therefore more suitable for providing input for clinical and policy decision-making. ${ }^{29}$

Furthermore, the CEA was performed from a societal perspective and entails all main costs for the intervention and usual care. Moreover, we included costs and effects during the intervention and up to 18 weeks after completing the exercise programme.

The study also has limitations. First, owing to the nature of the intervention, the patients were not blinded and about $50 \%$ of control groups of patients with breast and patients with colon cancer also reported high levels of physical activity, which may have led to an underestimation of the intervention effect. Second, we used diaries to assess costs. Using administrative data would have been an alternative; however, there is no complete registry of all cost data available in the Netherlands. Finally, not all patients were included in the CEA due to missing diaries. However, those who dropped out were not different in terms of demographic and medical background.

Our results indicate that physical exercise could be cost-effective for colon cancer. However, the limited 
study population may have caused a false-positive result and replication is needed. For breast cancer, costs were higher in the intervention group. Since 30\% of these costs could be contributed to the exercise programme, it might be worthwhile to look for possibilities to lower programme costs, for example, by offering the exercise programme to larger groups and in, for example, community centres instead of hospitals.

In conclusion, our results suggest that the 18-week exercise programme was cost-effective for colon cancer, but not for breast cancer.

\author{
Author affiliations \\ ${ }^{1}$ University Medical Center Utrecht, Julius Center for Health Sciences and \\ Primary Care, Utrecht, The Netherlands \\ ${ }^{2}$ Netherlands Comprehensive Cancer Organisation (IKNL), Utrecht, \\ The Netherlands \\ ${ }^{3}$ University Medical Center Utrecht, Cancer Center, Utrecht, The Netherlands \\ ${ }^{4}$ Department of Medical Oncology, St. Antonius Hospital, Nieuwegein, \\ The Netherlands \\ ${ }^{5}$ Department of Internal Medicine-Medical Oncology, Orbis Medical Center, \\ Sittard-Geleen, The Netherlands \\ ${ }^{6}$ Department of Internal Medicine, Medical Center Amersfoort, Amersfoort, \\ The Netherlands \\ ${ }^{7}$ Department of Surgery, Hospital Rivierenland, Tiel, The Netherlands \\ ${ }^{8}$ Department of Internal Medicine, Hofpoort Hospital, Woerden, \\ The Netherlands \\ ${ }^{9}$ Department of Internal Medicine, Diakonessenhuis, Utrecht, The Netherlands \\ ${ }^{10}$ School of Public Health, Imperial College London, London, UK \\ ${ }^{11}$ Centre for Nutrition, Prevention and Healthcare, National Institute for Public \\ Health and the Environment (RIVM), Bilthoven, The Netherlands
}

Acknowledgements The authors thank the participants and the professional staff at St. Antonius Hospital, Nieuwegein and Utrecht; Diakonessen Hospital, Utrecht; Meander Medical Centre, Amersfoort; Rivierenland Hospital, Tiel; Orbis Medical Centre, Sittard; Zuwe Hofpoort Hospital, Woerden and University Medical Center Utrecht, The Netherlands. Their participation made this study possible.

Contributors MJV, PHMP, EW and AMM initiated the collaborative project. MJV, ML, FE, HJB, MAJR, MV, DBH, PHMP, EW and AMM planned the project. MJV, CNSB, MJCB and AMM collected the data. ML, FE, HJB, MAJR, MV, DBH and EW provided the clinical expertise. AMM, MJCB, MJV, PHMP and GAW were responsible for data handling and data analyses. ML, FE, HJB, MAJR, MV and DBH recruited participants. AMM, MJCB, MJV, PHMP and GAW wrote the first draft. All authors contributed to the final manuscript.

Funding This work was supported by The Netherlands Organisation for Health Research and Development (ZonMw, project number: 171002 202), the Dutch Cancer Society (KWF Kankerbestrijding, project number: UU 2009-4473) and the Dutch Pink Ribbon Foundation (2011.W002.C100). All grants are unrestricted.

Competing interests None declared.

Patient consent Obtained.

Ethics approval Ethics Committee of UMC Utrecht.

Provenance and peer review Not commissioned; externally peer reviewed.

Data sharing statement No additional data are available.

Open Access This is an Open Access article distributed in accordance with the Creative Commons Attribution Non Commercial (CC BY-NC 4.0) license, which permits others to distribute, remix, adapt, build upon this work noncommercially, and license their derivative works on different terms, provided the original work is properly cited and the use is non-commercial. See: http:// creativecommons.org/licenses/by-nc/4.0/

\section{REFERENCES}

1. The Netherlands Cancer Registry. Comprehensive Cancer Centre, the Netherlands. 2015. 24-11-2015.

2. Bower JE. Cancer-related fatigue-mechanisms, risk factors, and treatments. Nat Rev Clin Oncol 2014;11:597-609.

3. Lawrence DP, Kupelnick B, Miller K, et al. Evidence report on the occurrence, assessment, and treatment of fatigue in cancer patients. $J$ Natl Cancer Inst Monographs 2004;(32):40-50.

4. Berger AM, Gerber LH, Mayer DK. Cancer-related fatigue: implications for breast cancer survivors. Cancer 2012;118(8 Suppl):2261-9.

5. Velthuis MJ, Agasi-Idenburg SC, Aufdemkampe G, et al. The effect of physical exercise on cancer-related fatigue during cancer treatment: a meta-analysis of randomised controlled trials. Clin Oncol (R Coll Radiol) 2010;22:208-21.

6. Cramp F, Byron-Daniel J. Exercise for the management of cancer-related fatigue in adults. Cochrane Database Syst Rev 2012; (11):CD006145.

7. Fong DY, Ho JW, Hui BP, et al. Physical activity for cancer survivors: meta-analysis of randomised controlled trials. BMJ 2012;344:e70.

8. Mewes JC, Steuten LM, ljzerman MJ, et al. Effectiveness of multidimensional cancer survivor rehabilitation and cost-effectiveness of cancer rehabilitation in general: a systematic review. Oncologist 2012;17:1581-93.

9. Sullivan R, Peppercorn J, Sikora K, et al. Delivering affordable cancer care in high-income countries. Lancet Oncol 2011;12:933-80.

10. Haines TP, Sinnamon P, Wetzig NG, et al. Multimodal exercise improves quality of life of women being treated for breast cancer, but at what cost? Randomized trial with economic evaluation. Breast Cancer Res Treat 2010;124:163-75.

11. Mutrie N, Campbell AM, Whyte F, et al. Benefits of supervised group exercise programme for women being treated for early stage breast cancer: pragmatic randomised controlled trial. BMJ 2007; 334:517.

12. Velthuis MJ, May AM, Koppejan-Rensenbrink RA, et al. Physical Activity during Cancer Treatment (PACT) Study: design of a randomised clinical trial. BMC Cancer 2010;10:272.

13. Travier N, Velthuis MJ, Steins Bisschop CN, et al. Effects of an 18-week exercise programme started early during breast cancer treatment: a randomised controlled trial. BMC Med 2015;13:121.

14. van Vulpen JK, Velthuis MJ, Steins Bisschop CN, et al. Effects of an exercise program in colon cancer patients undergoing chemotherapy. Med Sci Sports Exerc 2016;48:767-75.

15. Kemper H, Ooijendijk W, Stiggelbout M. Consensus about the Dutch physical activity guideline. Tijdschr Soc Geneeskunde 2000;78:180-3.

16. Hakkaart-van Rooijen L, Bouwmans CAM. Short form-health and labour questionnaire. Institute for Medical Technology Assessment, Erasmus University Rotterdam, 2010. http://www.bmg.eur.nl/ fileadmin/ASSETS/bmg/english/iMTA/Publications/Manuals Questionnaires/Manual SF-HLQ 2010.pdf

17. Consumer prices, price index 2013. 2013.

18. Hakkaart-van Rooijen L, Tan SS, Bouwmans CAM. Handleiding voor kostenonderzoek. Institute for Medical Technology Assessment, Ersmus University Rotterdam. 2010. http://www. zorginstituutnederland.nl/binaries/content/documents/zinl-www/ documenten/publicaties/overige-publicaties/ 1007-handleiding-voor-kostenonderzoek/Handleiding+voor +kostenonderzoek.pdf

19. Rabin R, de Charro F. EQ-5D: a measure of health status from the EuroQol Group. Ann Med 2014;33:337-43.

20. Lamers LM, McDonnell J, Stalmeier PF, et al. The Dutch tariff: results and arguments for an effective design for national EQ-5D valuation studies. Health Econ 2006;15:1121-32.

21. Manca A, Hawkins N, Sculpher MJ. Estimating mean QALYs in trial-based cost-effectiveness analysis: the importance of controlling for baseline utility. Health Econ 2005;14:487-96.

22. Fenwick E, Claxton K, Sculpher M. Representing uncertainty: the role of cost-effectiveness acceptability curves. Health Econ 2001;10:779-87.

23. Hamberg-van Reenen $\mathrm{H}$, Meijer $\mathrm{S}$. Wat is de kosteneffectiviteit van preventie?. 2015. http://www nationaalkompas nl/preventie/ kosten-van-preventie-nieuw/

24. Mewes JC, Steuten LM, Duijts SF, et al. Cost-effectiveness of cognitive behavioral therapy and physical exercise for alleviating treatment-induced menopausal symptoms in breast cancer patients. $J$ Cancer Surviv 2015;9:126-35.

25. Schmidt ME, Chang-Claude J, Seibold P, et al. Determinants of long-term fatigue in breast cancer survivors: results of a prospective patient cohort study. Psychooncology 2015;24:40-6. 
26. Schmidt ME, Wiskemann J, Armbrust P, et al. Effects of resistance exercise on fatigue and quality of life in breast cancer patients undergoing adjuvant chemotherapy: a randomized controlled trial. Int J Cancer 2015;137:471-80.

27. Steindorf K, Schmidt ME, Klassen O, et al. Randomized, controlled trial of resistance training in breast cancer patients receiving adjuvant radiotherapy: results on cancer-related fatigue and quality of life. Ann Oncol 2014;25:2237-43.
28. van Waart $\mathrm{H}$, Stuiver MM, van Harten $\mathrm{WH}$, et al. Effect of low-intensity physical activity and moderate- to high-intensity physical exercise during adjuvant chemotherapy on physical fitness, fatique, and chemotherapy completion rates: results of the PACES randomized clinical trial. J Clin Oncol 2015;33:1918-27.

29. Treweek S, Zwarenstein M. Making trials matter: pragmatic and explanatory trials and the problem of applicability. Trials 2009; 10:37. 